\title{
The 'Dark Side' of Social Capital: A Cross-National Examination of the Relationship Between Social Capital and Violence in Africa
}

\author{
Ludovico Alcorta $^{1}$ (D) . Jeroen Smits ${ }^{1} \cdot$ Haley J. Swedlund ${ }^{2} \cdot$ Eelke de Jong $^{1}$
}

Accepted: 28 December 2019 / Published online: 23 January 2020

(c) The Author(s) 2020

\begin{abstract}
Research and policy circles often emphasize the importance of social capital in achieving social transformation and economic development. There is also, however, potentially a 'dark side' to social capital. This study investigates the relationship between two different types of social capital—structural and cognitive — using two different measures of political violence: self-reported support for political violence and self-reported participation in political violence. We theorized that cognitive social capital will facilitate social cohesion within a community, enabling particularized trust between neighbours and a shared identity. On the other hand, structural social capital, or associational membership, potentially facilitates the diffusion of grievances and facilitates collective mobilization. Accordingly, we predict that higher levels of structural social capital will be associated with support for and participation in political violence, whilst higher levels of cognitive social capital will be associated with less support for and participation in political violence. We then test these predictions using Afrobarometer data on 40,455 individuals living in 27 African countries. Multivariate regression analysis confirms that indicators of structural and cognitive social capital have contrasting relationships with support for and participation in political violence. While particularized trust and national identity are negatively associated with political violence, religious and community associational membership are positively associated with political violence. In addition, we find that strength of attachment to a social identity, regardless of whether to an ethnic or national identity, is an important indicator of political violence.
\end{abstract}

Keywords Social capital · Political violence $\cdot$ Identity $\cdot$ Trust $\cdot$ Associational membership · Africa

Electronic supplementary material The online version of this article (https://doi.org/10.1007/s1120 5-019-02264-z) contains supplementary material, which is available to authorized users.

Ludovico Alcorta

1.alcorta@fm.ru.nl

1 Institute for Management Research, Department of Economics, Radboud University, Heyendaalseweg 141, 6525 AJ Nijmegen, The Netherlands

2 Centre for International Conflict - Analysis \& Management, Radboud University, Heyendaalseweg 141, 6525 AJ Nijmegen, The Netherlands 


\section{Introduction}

It is generally assumed that societies that experience high-levels of violence suffer from weak social capital (Blattman and Miguel 2010; Cassar et al. 2013; Grosjean 2014), and that social transformation requires an increase in the density of social ties (Colletta and Cullen 2000; De Luca and Verpoorten 2015). The World Development Report 2011, for example, considers the destruction of social capital to be one of the costs of violence and advocates for community-driven development programs in order to reconstruct social capital and strengthen social cohesion, especially in areas affected by conflict (World Bank 2011).

There is also, however, a potential 'dark side' to social capital (McDougall and Banjade 2015; Villalonga-Olives and Kawachi 2017). Portes (1998) notes that increased social capital can lead to negative consequences, such as constraints on individual freedom, downward levelling norms, ${ }^{1}$ and the social exclusion of persons not perceived to be members of the community. Instead of increasing trust and social cohesion, social capital mayunder certain circumstances-contribute to violence. For example, a cross-sectional study on social capital and adolescent behaviour using US data from 1994 to 1995, found that higher levels of participation in sports and club organizations actually increased tendencies towards fighting and the use of weapons (Wright and Fitzpatrick 2006). Additionally, a study on social capital and violence amongst young men in Beirut found that different indicators of social capital have ambiguous relationships with violence (El Hajj et al. 2011). How can we explain the divergent effects of social capital on individual violence?

Recent research indicates that it is important to distinguish between the structural and cognitive components of social capital when studying its relationship to violence (Dinesen et al. 2013; Hansen-Nord et al. 2014; Vazquez-Rodriguez and Lombe 2017). Structural social capital consists of a variety of forms of social organization, including networks, roles, rules, and procedures (Uphoff 2000). Examples include membership in trade unions, religious groups and political organizations. Cognitive social capital refers to "shared norms, values, attitudes, and beliefs" (Dasgupta and Serageldin 2000). For example, an idealized national identity might encourage its citizens to share common beliefs, such as the freedom of speech in the United States or 'liberté, egalité, fraternite' in France. Similarly, members of religious groups may expect each other to adhere to particular normative beliefs (Wimberley 1989).

Structural and cognitive social capital are often interlinked and mutually reinforcing of each other (Uphoff and Wijayaratna 2000). However, there is some evidence that these two types of social capital may have different effects on communal attitudes on violence (Brune and Bossert 2009). Case studies carried out in Guatemala (Dinesen et al. 2013) and Honduras (Hansen-Nord et al. 2014) on the relationship between social capital and exposure to violence find a negative relationship for cognitive social capital and violence, but a positive relationship for structural social capital and violence.

In this study, we investigate whether structural and cognitive social capital have opposing relationships with political violence across 27 countries in Africa. We use crossnational, individual-level data from the Afrobarometer; a unique public opinion survey that allows the testing of the relationship of multiple social capital indicators with two

\footnotetext{
1 In some instances, group solidarity is formed through a collective experience of adversity or rebellion. Since social cohesion depends on this shared belief, in order to sustain itself, the norms of a disadvantaged group will be made to reinforce the status quo, and push successful individuals out (Portes 1998).
} 
measures of self-reported political violence. We find that measures for structural and cognitive social capital have opposite relationships with self-reported political violence. Associational membership in religious and community groups is positively correlated with selfreported support and use of violence for a political cause. On the other hand, particularized trust is negatively correlated with self-reported support and use of violence for a political cause. We also find that, as the salience of an individual's identity increases, so does their reported support for and use of political violence.

Our findings contribute to the literature on social capital and political violence in three ways. First, we add to the literature disaggregating the effects of social capital on violence by empirically identifying positive and negative effects of social capital on violence for a political cause. Our research shows that some measures of social capital, in particular associational membership, may actually be linked to greater support and use of political violence. This result is important because it suggests that policies aimed at building social capital need to account for the potential negative impact of some types of social capital on political violence. Second, the study capitalizes on an innovative dataset measuring individual self-reported support for and use of violence for a political cause across 27 African countries. In contrast, most research in this field has focused on general violence (Dinesen et al. 2013; Hansen-Nord et al. 2014) or used less direct measures of political violence (Kasara 2017). By focusing solely on political violence, we are able to isolate the effect of social capital within the political sphere, the environment in which large-scale conflicts are usually fought. Moreover, this relationship is examined in the African context, which has been relatively underexplored in the social capital literature. Third, we find that the salience of identity is strongly associated to violence, regardless of whether it is ethnic or national. Social identities are key to determining individual behaviour, because they are intrinsic to people's own sense of identity, The bonds they create have strong emotional significance (Sambanis and Shayo 2013). Our research suggests that, the more that individuals are attached to a social identity, the more likely they will be prepared to 'defend' it.

The paper is organized into five sections. In the first section, we discuss the literature on the relationship between social capital and violence, defining structural and cogitative social capital in greater detail and outlining our main hypotheses. In the second section, we outline our methodological approach and sources of data. In the third section, we present our empirical results, while the fourth section discusses the relevance and context of these findings. Finally, the fifth section summarizes the study and the implications of its findings.

\section{Social Capital and Violence}

Social capital is commonly defined as the resources available to individuals and groups that arise from their formal and informal social networks (Putnam 1993). In the social science literature, research on social capital has generally focused on its positive attributes, such as its potential to minimize the risk of crime and violence by changing patterns of behaviour and/or increasing security (Avdeenko and Gilligan 2015; Hansen-Nord et al. 2016; Rosenfeld et al. 2001). Social capital is believed to decrease the costs of social transactions and strengthen communal ties (Lederman et al. 2002). This is argued to allow for the peaceful resolution of interpersonal and communal conflicts, as well as to help in overcoming free-rider problems (Ostrom and Ahn 2009). Civic engagement and interpersonal trust are thought to have a mutually reinforcing relationship (Brehm and Rahn 1997) and 
neighbourhood-based trust is associated with lower rates of criminal violence (Sampson and Raudenbush 1999).

However, social capital may also be conflict promoting, ${ }^{2}$ as it might encourage exclusionary behaviour (Portes 1998). Strong ties between members of a group might bar others from access. Participation in groups or communities often requires members to conform with the group, increasing social control and potentially restricting personal freedoms and individual thinking. In the years preceding the Rwandan genocide, for example, one of the Hutu Ten Commandments stated for example that 'Hutus must be firm and vigilant against their common Tutsi enemy' or would otherwise be considered as traitors themselves (Lemarchand 1996). When group solidarity is based on a common negative experience, downward levelling norms might also play a role. For instance, Rubio (1997) blames 'perverse' social capital for violence and criminality pervasiveness in Colombia, and Ostrom and Ahn (2009) argue that criminal organizations rely on the cohesive power of social capital in order to operate.

As the literature suggests, the nature of the relationship between social capital and violence is ambiguous, which might explain why the empirical research on social capital and violence has found mixed results. For example, Lederman et al. (2002) found that associational membership is positively correlated with crime rates in some cases and negatively correlated in others. In his examination of Hindu-Muslim conflict in India, Varshney (2001) found that if associational membership was organized along intra-ethnic lines, it could exacerbate ethnic violence. When studying the effect of social capital on young men in Beirut, El Hajj et al. (2011) found that some social capital indicators, such as group membership, trust in people from the area, social support and the reciprocal exchange of non-material favours, were positively correlated with physical fighting. Other social capital indicators, such as the relationship between social networks and fighting, were ambiguous.

Social capital is a broad term that consists of multiple indicators compounded together. Scholars often, for example, distinguish between bonding and bridging social capital (Colletta and Cullen 2000; Putnam 2000). Bonding social capital is supposed to strengthen the connection and sense of belonging within the group, whereas bridging ties created by associations that cut across group lines are supposed to dilute the bonds within groups (Varshney 2001). In this paper, we consider the distinction made by Uphoff (2000) between structural social capital (social network approach) and cognitive social capital (social cohesion approach). This distinction has been less addressed in the social capital literature, but points to two dimensions of social capital that may have different relationships to political violence (Dinesen et al. 2013; Hansen-Nord et al. 2014). Structural social capital consists of social networks, both formal and informal, which are accompanied by procedures and rules. Examples of this include sports clubs, trade unions and religious organizations (Bhavnani and Backer 2007; De Silva et al. 2006). On the other hand, cognitive social capital refers to shared norms, values, attitudes, and beliefs (Krishna and Shrader 2000). Commonly used indicators of cognitive social capital include trust among community members (Dowla 2006; Bisung et al. 2014) and the adherence to a national identity (Langer et al. 2017).

\footnotetext{
${ }^{2}$ Here is it important to note that the relationship between social capital and conflict has been theorized to work in both directions. Scholars have argued that conflict may erode or shape social capital into new forms (Cassar et al. 2013; De Luca and Verpoorten 2015; Deng 2010) and these new forms of social relations can potentially become the basis for further conflicts (Rohner et al. 2013; Schaub 2014). In this project, however, we focus on how different types of social capital can have divergent associations with violence.
} 
Both dimensions of social capital are often tied together, and can reinforce each other (Uphoff and Wijayaratna 2000). The main difference between them is that structural social capital is considered to be the resources available to individuals through their access to social networks, whilst cognitive social capital is viewed as an asset for both the individual and the community. Cognitive social capital measures the integration of the group and forms the basis for social bonds and collaboration. These two dimensions have been found to have diverse effects on violence. For example, when examining social capital in the context of exposure to violence in Latin American countries, scholars found that structural and cognitive social capital appear to have opposing associations with violence. Structural social capital increased the risk of violence, while cognitive social capital reduced the risk of violence (Dinesen et al. 2013; Hansen-Nord et al. 2014). The differences between these two dimensions of social capital with respect to their potential relationship with violence are explained in more detail below.

\section{Structural Social Capital}

We expect a positive relationship between structural social capital and individual-level violence. Structural social capital refers to the resources accessible to people through formal and informal networks and is thus characteristic of a social network approach to social capital (Dinesen et al. 2013). These networks manifest through associational membership in formal and informal organizations or everyday civic engagement (De Silva et al. 2006). Varshney (2001) argues that associational forms of engagement have a stronger influence on peace or violence than daily civic engagement for two reasons. First, associational membership serves to organize communities and provides dedicated platforms for engagement. Second, associations often have objectives that go beyond quotidian interactions. This imparts a robustness that allows associations to withstand exogenous shocks and to influence politics. The latter, however, is contingent on the nature of the association. If associational membership is interethnic, it can provide a constraint against the polarization of communities. However, if it is intra-ethnic, it will only reinforce the divisions within a society.

In addition, organizational members may cooperate for benign or malicious reasons (Portes 1998). Even originally benign cooperative ventures can over time become a basis for organised violence (Schaub 2014). The build-up of social capital within groups may have particularly negative consequences, if groups promote exclusionary practices based on hate and intolerance with other groups (Fukuyama 2000). Under such circumstances, or if groups are already associated with violence (i.e. gangs), individuals who might otherwise be peaceful citizens could be persuaded by other group members to adopt more violent behaviour (El Hajj et al. 2011). Several studies have found membership and cooperation within communal organizations can increase the risk of violence (Dinesen et al. 2013; Hansen-Nord et al. 2014; Schaub 2014). Groups containing pro-social individuals who are willing to cooperate with each other are usually more capable of survival in inter-group conflict (Grosjean 2014).

Information on opportunities can also diffuse through the network, meaning that better connected individuals will have access to more information and will obtain it faster (Shahabuddin McDoom 2014). The size of an individual's network can therefore affect their participation in violent collective action, since the more connections a person has, the more opportunities for participation will be presented to them. Furthermore, people who are 
more actively engaged in the civic society through e.g. political activities, experience more "time at risk", and are thus more exposed to violence compared to people who participate less in such community activities (Hansen-Nord et al. 2014). Active participation in civil society might also mean that individuals are targeted more by the authorities or other individuals because of their political engagement (Piquet Carneiro 2000), which could increase the risk of them being involved in violent encounters.

An important consideration is that associational membership is only likely to have an effect on individuals if their involvement in an organization is relatively frequent (Bhavnani and Backer 2007). People who belong to an organization but do not participate often in its activities are not strongly subjected to its influence. The more active an individual is, the more likely they will be influenced by the organization, and the more predisposed they will be to engage in collective action for its cause. This relationship is mutual, as the individual is likely to assert their own values and interests - whether positive or negative-on others in the organization as their influence and participation grows. Elite manipulation theory stipulates that groups can be exploited by their leaders, who may use their power to mobilize the group in order to advance their own interests (Fearon and Laitin 2000). Taking these arguments into account, our prediction is therefore that:

H1 Individuals that self-report that they are members of religious groups and voluntary associations or community groups are more likely to support or use violence.

\section{Cognitive Social Capital}

In contrast, we predict that cognitive social capital indicators of trust and adherence to national identity will be negatively related to violence. According to the social cohesion approach popularized by Coleman (1990) and Putnam (2000), cognitive social capital comprises the shared beliefs, values, trusts and norms between people that stimulate cooperation (Uphoff 2000). In an effort to measure social cohesion, Langer et al. (2017) recently proposed a perceptions-based index incorporating three components: inequality, the level of trust and adherence to a national identity. Of these, trust and identity are most frequently used as indictors of cognitive social capital (De Silva et al. 2006; El Hajj et al. 2011; Mitchell and Bossert 2007).

Trust enables individuals to take risks in dealing with others, solve collective action problems, or act in ways that are contrary to self-interest (Levi 1998). The concept of trust can be categorized into generalized trust, particularized trust, and strategic trust (Smith 2010). Generalized and particularized trust have a moral foundation, because they require people to have faith in others (Uslaner 2002). Strategic trust is more related to rational choice theory, as it refers to individuals' expectations that others will act with their own best interests in mind (Hardin 2002). This study shall focus mainly on the two types of moralistic trust, since these are the most commonly used measures of trust in social science research (Carpiano and Fitterer 2014). Moreover, people do not usually associate trust with rational choice outside of game theory (Abbott and Freeth 2008).

Generalized trust is defined as an individual's evaluation of the trustworthiness of the average person in society and has been hypothesized to connect people in social spheres with people unlike themselves (Glanville and Paxton 2007). This concept reflects more about a individual's beliefs regarding the moral standing of their society than their beliefs about any specific relationships (Sztompka 1999). In the context of violence, higher 
levels of generalized trust are likely to reduce the risk of communal violence by mitigating any potential incentives for conflict between groups. Low generalized trust in society has the opposite effect and is associated with the potential for social conflict in countries (Delhey and Newton 2005). When the level of trust between groups in a country is low, it is also easier for political leaders to obtain support for violent collective action (Kasara 2017).

Particularized trust concerns trust in networks of close relations (Uslaner 2002), such as trust in family members, neighbours, or in-group members, and is considered to reflect the resources and relationships available in an individual's close network (de Silva et al. 2006). Particularized trust symbolizes the belief that specific people or groups are trustworthy, which might be especially relevant when individuals are only exposed to people from their own community; i.e. in rural areas. Despite particularized trust being more relational than generalized trust, empirical evidence on the relationship between particularized trust and conflict has found similar results as for generalized trust. Vial et al. (2010), for example, report higher rates of violence when trust between neighbours is low, and Cuesta and Alda (2012) find a negative relationship between interpersonal trust and victimization in communities. An increase in either particularized or generalized trust is therefore expected to be correlated to a decrease in violence, which forms the premise for the second hypothesis:

H2 Individuals that self-report higher levels of particularized and generalized trust are less likely to use violence.

Putnam (2000) argued that to restore social capital, overarching identities need to be formed. A shared sense of belonging can promote social cohesion (Holtug 2017). The formation of a national identity functions as a form of social cohesion by superseding divisions between sub-national identities, such as ethnicity (Charnysh et al. 2015). Examining social identification and conflict, Sambanis and Shayo (2013) find that when individuals identify more with the nation than their ethnic group, the chance of conflict is reduced.

In states where the conditions fail to foster a national identity-and thus ethnic identity is relatively more salient - the lack of solidarity within the national community and the more salient ethno-political cleavages in society are also likely to increase the risk of social fragmentation, exclusion and oppression, increasing the likelihood of conflict between individuals and groups. The case of Rwanda illustrates the complex and important role of social cohesion with respect to violence. The interethnic conflict between Hutus and Tutsis in 1994 destroyed the social fabric of society, whilst simultaneously strengthening the intra-Hutu bonds that helped make the genocide possible (Colletta and Cullen 2000). In its aftermath, Rwandan policymakers have pursued policies of nation-building and deethnicisation with the aim of achieving social cohesion (Purdeková 2008). Consequently, the following hypothesis tests for the an inverse relationship between the formation of a national identity and violence:

H3a Individuals who self-report that they identify with the nation state are less likely to support and use violence.

In addition, the strength of an individual's social identity can determine how strongly they share the norms and beliefs of their community, and how much they related to collective grievances (Langer et al. 2017; Wimberley 1989). Ethnic conflict is thought to be spurred on by collective grievances, but only if members of a disadvantaged group identify 
strongly with it (Stewart 2008). The strength of identity might also be an important factor that affects perceptions of discrimination and consequently the risk of violence (Charnysh et al. 2015). Individuals who identify with the nation are more likely to perceive their fate to be tied to the nation's fate and are more likely to trust other co-nationals outside of their ethnic group (Robinson 2016). Overlapping identities can also mitigate the relationship between identity and violence by diluting the extent that individuals value their association to any particular identity. This would signify that when grievances are not shared by the group's members, it will be more difficult to mobilize an individual towards (violent) collective action in support of the group or country. A final hypothesis thus examines whether the salience of identity is related to violence:

H3b Individuals who self-report that they more strongly identify with either the nation state or their ethnic group are more likely to support and use violence.

\section{Data and Methods}

\subsection{Data}

To test our predictions, we utilize cross-sectional data for 40,455 individuals living in 27 African countries derived from the fifth round of the Afrobarometer surveys. This survey provides information on public opinions in African countries on issues such as democracy, governance and economic conditions (Afrobarometer 2012). For the survey, a sample of 1200 or 2400 randomly selected individuals were interviewed in each country. Sampling was conducted at all stages with the probability of being selected for the survey comparable to their country's population size. Therefore, larger and more populated countries have a greater probability of being selected in the sample. The surveys reduce the likelihood that distinctive ethnic groups are left out of the sample by stratifying the sample according to the subnational area. Only the fifth round of surveys is utilized because it is the only round which discerns between ethnic identities and includes variables on support for and the use of violence.

\subsection{Violence}

To examine the relationship between social capital and violence, we employ both an indirect and direct measure of violence for a political cause: support for political violence and use of political violence. The first variable measures the respondent's reported attitude towards political violence. The respondents are read two statements: "Statement 1-the use of violence is never justified in [respondent's country] politics today" and "Statement 2-In this country, it is sometimes necessary to use violence in support of a just cause", and subsequently asked with which statement they agree more. Answers are on a five-point scale, ranging from agreeing entirely with the first statement to agreeing with entirely with the second statement, and the midway point being 'agreeing with neither'. This measure is an indirect indicator of violence since it does not consider actual or prospective behaviour. Nevertheless, it is conceivable that respondents who approve of violence are more likely to use violence than those who cannot justify its use. Collective attitudes of a society might discourage violent behaviour through the norms that people observe and internalize. In contrast, a lack of social standards could facilitate rebel recruitment and violent behaviour 
within a community. This is found to be the case in sub-Saharan Africa, where regions with high levels of popular acceptance of violence are positively related to conflict (Linke et al. 2015).

The second variable measures self-reported use of political violence. Most measures of violence in studies on social capital tend to be indirect (Kasara 2017; Schaub 2014) or examine general violence (Dinesen et al. 2013; Hansen-Nord et al. 2014). Quite uniquely, the Afrobarometer survey provides a direct indicator for the reported participation of the respondents in political violence by asking them whether they have personally engaged in the use of force or violence for a political cause. This measure separates violence in the political context, such as protests, rebellions or civil wars, from other types of violence, such as criminal or domestic violence. Responses are structured to capture the frequency of the individual's actions in the following order-never (0), never but would if they had the chance (1), once or twice (2), several times (3), and often (4). Because of the social stigma against violence (Table 1 shows that almost $81 \%$ of the respondents in the survey do not support the use of violence), we expect the reported use of violence to be under-reported.

\subsection{Social Capital}

Structural social capital is measured through the membership of individuals in two types of formal associations: members of religious groups outside of regular worship services and members of voluntary association or community groups. In the Afrobarometer, respondents can select one of four possible responses on an ordinal scale including non-member (0), inactive member (1), active member (2), and official leader (3). Given that these categories do not correspond to a linear scale, we also transformed them into sets of dummy variables, with a separate dummy for each category.

Cognitive social capital is measured through several indicators for trust and shared identity. We included two indicators for trust: particularized trust and generalized trust. The particularized trust measure asks respondents whether they do not trust their neighbours (0), or whether they trust them just a little (1), somewhat (2) or a lot (3). ${ }^{3}$ The generalized trust variable is dichotomous measuring trust in society in general. Particularized trust provides a more direct and accurate measurement of how trust functions as social capital within an individual's direct environment, whereas generalized trust is an "affective orientation'" towards others that indicates their level of tolerance (Rudolph and Popp 2010).

The measure for identity is gauged by asking the respondents whether they were more strongly attached to their own ethnic group or their nationality. Thus, the variable represents a spectrum, with identification to the nation state on one end and identification with the ethnic group on the other. To examine the importance of identity salience, we split the measure up into two variables: national identity and identity salience. National identity is measured by whether the respondent feels mainly or only ethnic (0), equally ethnic and national (1), or mainly or only national (2). Identity salience indicates the strength of the individual's attachment to their identity, be it ethnic or national. The variable is categorised as 0 if the respondent does not feel more attached to one or the other; 1 if they feel more attached to their ethnic or the national identity; and 2 if they feel attached to only their ethnic or national identity.

\footnotetext{
3 The exact phrasing of the questions is as follows: "How much do you trust each of the following types of people: Your neighbors?".
} 
Table 1 Descriptive statistics summary table for selected independent and dependent variables in 27 African countries. Source: Afrobarometer Surveys Round 5. Response categories provided in italics

\begin{tabular}{|c|c|c|c|c|}
\hline Variables & Mean & SD & Minimum & Maximum \\
\hline \multicolumn{5}{|l|}{ Violence } \\
\hline Support for violence & 1.02 & 1.29 & 0 & 4 \\
\hline Agree very strongly with Statement $1(\%)$ & 0.47 & 0.50 & 0 & 1 \\
\hline Agree with Statement 1 (\%) & 0.31 & 0.46 & 0 & 1 \\
\hline Agree with neither statement (\%) & 0.03 & 0.17 & 0 & 1 \\
\hline Agree with Statement $2(\%)$ & 0.11 & 0.32 & 0 & 1 \\
\hline Agree very strongly with Statement $2(\%)$ & 0.08 & 0.27 & 0 & 1 \\
\hline Used force or violence for a political cause & 0.15 & 0.54 & 0 & 4 \\
\hline Never $(\%)$ & 0.90 & 0.30 & 0 & 1 \\
\hline Never, but would consider (\%) & 0.07 & 0.25 & 0 & 1 \\
\hline A few times (\%) & 0.02 & 0.12 & 0 & 1 \\
\hline Sometimes $(\%)$ & 0.01 & 0.01 & 0 & 1 \\
\hline Often $(\%)$ & 0.01 & 0.01 & 0 & 1 \\
\hline \multicolumn{5}{|l|}{ Structural social capital } \\
\hline Religious association & 0.90 & 1.00 & 0 & 3 \\
\hline Non-member (\%) & 0.50 & 0.50 & 0 & 1 \\
\hline Inactive member (\%) & 0.17 & 0.37 & 0 & 1 \\
\hline Active member (\%) & 0.27 & 0.45 & 0 & 1 \\
\hline Leader $(\%)$ & 0.06 & 0.24 & 0 & 1 \\
\hline Voluntary or community association & 0.69 & 0.97 & 0 & 3 \\
\hline Non-member (\%) & 0.62 & 0.49 & 0 & 1 \\
\hline Inactive member (\%) & 0.14 & 0.34 & 0 & 1 \\
\hline Active member (\%) & 0.19 & 0.39 & 0 & 1 \\
\hline Leader $(\%)$ & 0.06 & 0.23 & 0 & 1 \\
\hline \multicolumn{5}{|l|}{ Cognitive social capital } \\
\hline Particularized trust & 1.79 & 1.01 & 0 & 3 \\
\hline Not at all (\%) & 0.13 & 0.34 & 0 & 1 \\
\hline Just a little (\%) & 0.25 & 0.43 & 0 & 1 \\
\hline Somewhat (\%) & 0.33 & 0.47 & 0 & 1 \\
\hline$A \operatorname{lot}(\%)$ & 0.30 & 0.46 & 0 & 1 \\
\hline Generalized trust & 0.19 & 0.39 & 0 & 1 \\
\hline Identity salience & 1.03 & 0.92 & 0 & 2 \\
\hline Weak $(\%)$ & 0.40 & 0.49 & 0 & 1 \\
\hline Intermediate (\%) & 0.16 & 0.37 & 0 & 1 \\
\hline Strong $(\%)$ & 0.44 & 0.50 & 0 & 1 \\
\hline National identity & 1.38 & 0.67 & 0 & 2 \\
\hline Ethnic (\%) & 0.11 & 0.31 & 0 & 1 \\
\hline Both (\%) & 0.40 & 0.49 & 0 & 1 \\
\hline National (\%) & 0.49 & 0.50 & 0 & 1 \\
\hline \multicolumn{5}{|l|}{ Individual controls } \\
\hline Perceived collective grievances & 0.64 & 0.94 & 0 & 3 \\
\hline Never $(\%)$ & 0.61 & 0.49 & 0 & 1 \\
\hline Sometimes (\%) & 0.22 & 0.41 & 0 & 1 \\
\hline Often (\%) & 0.10 & 0.31 & 0 & 1 \\
\hline
\end{tabular}


Table 1 (continued)

\begin{tabular}{lrrll}
\hline Variables & \multicolumn{1}{c}{ Mean } & \multicolumn{1}{c}{ SD } & Minimum & Maximum \\
\hline Always (\%) & 0.07 & 0.26 & 0 & 1 \\
Education (years) & 6.75 & 4.91 & 0 & 17 \\
Wealth (IWI) & 48.04 & 24.98 & 0 & 100 \\
Urbanized (\%) & 0.36 & 0.48 & 0 & 1 \\
Female (\%) & 0.50 & 0.50 & 0 & 1 \\
Age (years) & 37.04 & 14.51 & 18 & 105 \\
Group controls & & & & \\
Education deprivation (years) & 0.05 & 1.20 & -6.47 & 4.96 \\
Wealth deprivation (IWI) & 0.29 & 8.51 & -31.46 & 27.50 \\
Small population size & -310.48 & 395.31 & -1473 & 403.80 \\
Distance from power & 1.62 & 0.61 & 1 & 4 \\
Religious fractionalization & 0.23 & 0.17 & 0 & 0.68 \\
Conflict in past 5 years (\%) & 0.19 & 0.39 & 0 & 1 \\
\hline
\end{tabular}

\subsection{Controls}

We included several control variables at both the individual and group level. At the individual level, we controlled for the respondent's perception of discrimination against their ethnic group on a scale of 0 (never) to 3 (always). We also controlled for their age, education and wealth level and whether the individual lives in a rural (0), semi-rural (0.5) or urban environment (1). Education is measured in terms of years of schooling received, and the measure for wealth ranges from 0 till 100, based on an index from assets, housing characteristics and public utilities (Smits and Steendijk 2015).

We also incorporate several controls based on the socioeconomic and demographic characteristics of the ethnic groups (Stewart 2008). The respondents were asked to identify which ethnic community, group or tribe they belonged to. Ethnic groups for which only a few observations were available (less than $1 \%$ ) were incorporated into larger ethnolinguistically similar clusters, or omitted from the analysis. The group-level controls were created by aggregating data to the group level for all ethnic groups that were available in the survey. Relative deprivation in education, wealth, and population was measured by subtracting the national averages of these variables from the ethnic group averages. Furthermore, to control for political grievances we incorporate a measure of distance from power derived from the Ethnic Power Relations (EPR) dataset (Vogt et al. 2015). The EPR dataset includes data on access to power on the national level for politically-relevant groups by coding the extent that representatives of ethnic groups hold executive-level power in the government. The distance from power measure is an inverted ordinal variable consisting of four categories extracted from the EPR dataset: senior partner (1), junior partner (2), powerless (3) and discriminated (4). Groups coded as irrelevant were excluded from the analysis. Finally, using UCDP data we include a dichotomous variable to control for whether the respondent's ethnic group has been involved in conflict in the 5 years prior to the survey (2007-2011).

Finally, although the focus of the current study is not on the distinction between bridging and bonding social capital, we still wanted to control for this distinction in our analysis. To do so, we have incorporated an indicator of religious heterogeneity at the ethnic group 
level in our model. This "religious fractionalization" variable measures the probability that two random individuals in the same ethnic group belong to different religions. Religious fractionalization (RF) is calculated using the Herfindahl concentration formula, $R F=1-\sum_{i=1}^{n}\left(s_{i}^{2}\right)$, where $s_{i}$ is the share of religion $i(i=1, \ldots, n)$. We assume that a religiously homogeneous ethnic group (nearing 0 on the RF index) indicates the presence of bonding social capital, whereas a religiously heterogeneous ethnic group (nearing 1 on the RF index) indicates the presence of bridging social capital. We also ran the analysis with a religious polarization measure using Reynal-Querol's (2002) polarization index to examine the interplay between the group size and the intergroup distance. However, as the effect was the same, so only the fractionalization index variable is included in the final models.

\subsection{Analyses}

To test the hypotheses, we employed ordered logistic multilevel regression analysis. Twolevel versions of the models are used to address the nesting of respondents within ethnic groups. Clustering at the national level is taken into account by including fixed-effects country dummies in all models. Separate models are estimated for the two dependent variables: support for and the use of violence. The choice for ordered logit models is due to the nature of the dependent variables, which are ordered but the differences in categories cannot be clearly distinguished linearly. We use separate models with dummies to test for specific effects of the different categories in the structural social capital variables. We test for nonlinearity of the independent variables by including quadratic terms in the models and keeping them in the model in case of significant nonlinearity. As a robustness check, we converted the dependent variables into dummies, separating the population that has used violence for a political cause and the population that supports violence into single groups and conduct the same analysis using a binary logistic regression model. The results are essentially the same as in the main analysis and can be found in the Supplementary Table.

Missing values on the variables were addressed by utilizing the dummy variable adjustment procedure (Allison 2001). As a robustness test, we studied effects of previous conflicts by including a dummy variable indicating whether the ethnic group of the respondent was involved in ethnic conflict in the last 5 years. This information was derived from the Armed Conflict, One-Sided and Non-State datasets from the Uppsala Conflict Data Program (Allansson et al. 2017; Eck and Hultman 2007; Sundberg et al. 2012).

\section{Results}

The descriptive summary in Table 1 provides details on the variables included in the analysis. On average, most individuals agree with the statement that violence is never justified (46.9\%). Overall, there are far more people willing to justify violence than those that actually commit acts of violence. The number of individuals that report having committed acts of violence is quite low, consisting of just $3.1 \%$ of the respondents. This is not surprising given the stigma that most societies have against the use of violence; a belief which is illustrated by the lack of support for violence in the first outcome variable (22\% justify its use under certain circumstances).

In regards to the measures of structural social capital, individuals are about equally likely to be part of religious associations as not, with $50.2 \%$ being members, of which 
$27.5 \%$ self-classify as an active member and $6 \%$ as a leader. On average, respondents tend to be less involved in community associations, with only $38.3 \%$ reporting that they are a member, of which only $18.9 \%$ self-classify as an active member and $5.8 \%$ as a leader.

For the measures of cognitive social capital, trust in one's neighbour is quite high, while generalized trust is low. On average, individuals report that they are quite trusting of their neighbours; $62.2 \%$ trust their neighbours somewhat and $29.6 \%$ trust them a lot. However, only $19.3 \%$ of the respondents agree that most people in society can be trusted, with the large majority believing that one must be very careful $(80.7 \%)$. Responses to the national identity variable suggest that almost half of the respondents (49.1\%) identify themselves more nationally than ethnically, while responses to the identity salience variable suggest that the results for salience of identity (to either the nation or their ethnic group) are polarized, with $40.2 \%$ having a weak identification and $43.6 \%$ having a strong identification.

With respect to the control variables, most individuals have never perceived any form of discrimination towards their ethnic group (60.7\%), whereas $17.7 \%$ report having experienced frequent or consistent discrimination. On average, respondents have received 6.7 years of education and have a wealth level of 48 on the 100-point IWI scale. Respondents live mainly in rural areas (only $36.3 \%$ are urbanized) and are equally likely to be male or female (50\%). They are on average 37 years old. The descriptive statistics for the group level controls illustrate that education deprivation ranges from 6.5 years below to 5 years above the national average, whilst wealth deprivation varies from -27.5 to 42.9 on the IWI scale. Group sizes range from 1473 people fewer than the country mean to 403.8 more than the country mean in the sample population. Groups are usually included in government, with the average score on the distance from power variable (1.62) falling between the junior and senior partner categories. Finally, religious fractionalization scores range from 0 to 0.68 , with the average ethnic group leaning more towards religiously homogeneity $(0.23)$. Notably, $19 \%$ of the groups included in the analysis have been involved in conflict over the past 5 years.

The results of the multivariate regression models are presented in Table 2. The first model represents the analysis with the reported support for violence as the outcome variable, whilst the second model presents the regression results for the reported use of violence as the outcome variable. The third and fourth models include the same dependent variables respectively, but introduce dummy variables for the subcategories in the associational membership indicators, using non-members of religious and communal associations as the reference categories.

Starting with structural social capital, in Models 1 and 2 we can observe that religious membership significantly and positively correlates with self-reported use of violence, but not with self-reported support for violence. When we look more in detail at the subcategories in Models 3 and 4, we observe that inactive members of religious groups are significantly more likely to support and use violence than non-members. Active members and leaders of these groups are also more likely than non-members to report using violence, although the effect is weaker. Community membership has a positive correlation with both outcome variables. In Model 3, active members and leaders of community groups are significantly more likely to justify violence than non-members, whilst in Model 4, it is evident that each stepwise increase in participation is progressively more associated to the use of violence, with community leaders being the most violent category. Overall, the coefficients for both the associational membership variables provide strong support for the first hypothesis, which posits that being a self-reported member of an association will be correlated with a higher propensity for violence. 
Table 2 Multilevel ordered logit coefficients for multivariate associations between selected independent variables and support for and use of violence in 27 African countries

\begin{tabular}{|c|c|c|c|c|}
\hline Variables & $\begin{array}{l}\text { Support for violence } \\
\text { Model } 1\end{array}$ & $\begin{array}{l}\text { Use of violence } \\
\text { Model } 2\end{array}$ & $\begin{array}{l}\text { Support for violence } \\
\text { Model } 3\end{array}$ & $\begin{array}{l}\text { Use of violence } \\
\text { Model } 4\end{array}$ \\
\hline \multicolumn{5}{|l|}{$\begin{array}{l}\text { Structural social } \\
\text { capital }\end{array}$} \\
\hline $\begin{array}{l}\text { Religious member- } \\
\text { ship }\end{array}$ & $-0.005(0.006)$ & $0.030 * * *(0.007)$ & & \\
\hline Non-member & & & Reference & Reference \\
\hline Inactive member & & & $0.047 * *(0.016)$ & $0.131 * * *(0.019)$ \\
\hline Active member & & & $-0.024(0.014)$ & $0.067 * * *(0.017)$ \\
\hline Leader & & & $-0.001(0.024)$ & $0.062 *(0.028)$ \\
\hline $\begin{array}{l}\text { Community member- } \\
\text { ship }\end{array}$ & $0.028 * * *(0.006)$ & $0.107 * * *(0.007)$ & & \\
\hline Non-member & & & Reference & Reference \\
\hline Inactive member & & & $0.030(0.017)$ & $0.182 * * *(0.019)$ \\
\hline Active member & & & $0.070^{* * *}(0.015)$ & $0.213 * * *(0.018)$ \\
\hline Leader & & & $0.057 *(0.025)$ & $0.304 * * *(0.028)$ \\
\hline \multicolumn{5}{|l|}{$\begin{array}{l}\text { Cognitive social } \\
\text { capital }\end{array}$} \\
\hline Particularized trust & $-0.026^{* * *}(0.006)$ & $-0.034 * * *(0.007)$ & $-0.027 * * *(0.006)$ & $-0.035^{* * *}(0.007)$ \\
\hline Generalized trust & $0.006(0.015)$ & $0.078 * * *(0.017)$ & $0.005(0.015)$ & $0.076 * * *(0.017)$ \\
\hline Identity salience & $0.041 * * *(0.007)$ & $0.048 * * *(0.009)$ & $0.041 * * *(0.007)$ & $0.047 * * *(0.009)$ \\
\hline National identity & $-0.020(0.010)$ & $-0.010(0.012)$ & $-0.020(0.010)$ & $-0.010(0.012)$ \\
\hline \multicolumn{5}{|l|}{ Individual controls } \\
\hline $\begin{array}{l}\text { Perceived Discrimi- } \\
\text { nation }\end{array}$ & $0.144 * * *(0.019)$ & $0.102 * * *(0.022)$ & $0.142 * * *(0.019)$ & $0.101 * * *(0.022)$ \\
\hline $\begin{array}{l}\text { Perceived } \\
\quad \text { Discrimination }^{2}\end{array}$ & $-0.035^{* * *}(0.007)$ & $-0.011(0.008)$ & $-0.035^{* * * *}(0.007)$ & $-0.010(0.008)$ \\
\hline Education & $-0.001(0.001)$ & $-0.006^{* * *}(0.002)$ & $-0.000(0.001)$ & $-0.006 * *(0.002)$ \\
\hline Wealth & $0.001(0.001)$ & $0.004 * * *(0.001)$ & $0.001(0.001)$ & $0.004 * * *(0.001)$ \\
\hline Wealth $^{2}$ & $-0.000(0.000)$ & $-0.000^{* * *}(0.000)$ & $-0.000(0.000)$ & $-0.000 * * *(0.000)$ \\
\hline Urbanized & $0.019(0.014)$ & $-0.014(0.017)$ & $0.020(0.014)$ & $-0.011(0.017)$ \\
\hline Female & $-0.032 * *(0.011)$ & $-0.087 * * *(0.013)$ & $-0.032 * *(0.011)$ & $-0.091 * * *(0.013)$ \\
\hline Age & $-0.003^{* * *}(0.000)$ & $-0.004 * * *(0.000)$ & $-0.003^{* * *}(0.000)$ & $-0.003 * * *(0.000)$ \\
\hline \multicolumn{5}{|l|}{ Group controls } \\
\hline Education deprivation & $0.002(0.015)$ & $-0.010(0.016)$ & $0.003(0.015)$ & $-0.008(0.016)$ \\
\hline Wealth deprivation & $0.003(0.002)$ & $0.002(0.002)$ & $0.003(0.002)$ & $0.002(0.003)$ \\
\hline Small population size & $-0.000(0.000)$ & $-0.000(0.000)$ & $-0.000(0.000)$ & $-0.000(0.000)$ \\
\hline $\begin{array}{l}\text { Distance from power } \\
\text { (EPR) }\end{array}$ & $-0.037(0.030)$ & $-0.057(0.030)$ & $-0.037(0.030)$ & $-0.056(0.030)$ \\
\hline $\begin{array}{l}\text { Religious fractionali- } \\
\text { zation }\end{array}$ & $0.007(0.104)$ & $0.004(0.107)$ & $0.004(0.104)$ & $-0.003(0.107)$ \\
\hline $\begin{array}{l}\text { Ethnic conflict in past } \\
5 \text { years }\end{array}$ & $0.040(0.063)$ & $-0.035(0.065)$ & $0.040(0.064)$ & $-0.034(0.065)$ \\
\hline Observations & 40,308 & 40,455 & 40,308 & 40,455 \\
\hline
\end{tabular}

${ }^{*} p<.05 ; * * p \leq .01 ; * * * p \leq .001$. Standard errors in parentheses. Country fixed effects and missing dummies not reported. For structural social capital variables, non-members are used as the reference category 
With respect to cognitive social capital variables, the results are more nuanced. We find a negative relationship between the indicator for particularized trust (trust in neighbours) and both support for and the use of violence in all model specifications. However, this is not the case for generalized trust, which is positively and significantly associated to the use of violence in Model 2 and 4, but has no significant effect on support for violence in Models 1 and 3. Particularized trust is the most consistent result, providing strong support for the second hypothesis on self-reported trust measures being negatively correlated to violence.

The national identity variable does not offer any evidence for H3a in Table 2. Although the direction of the national identity coefficients is negative, the significant effect in the multivariate models does not hold. We do, however, find support for the hypothesis on identity salience (H3b). Identity salience is highly significant in all models, and positively correlated to both dependent variables on violence. Here the relationship with violence becomes stronger the more important that individuals perceive their identity to be, irrespective of it being ethnic or national. When both identities overlap and the respondent does not have strong sentiment for either type, both their support for and use of violence decrease significantly.

Regarding the control variables, a higher perception of ethnic discrimination has a strong and positive association throughout all model specifications. When support for violence is the dependent variable (Models 1 and 3), the relationship with discrimination is nonlinear and the effect of discrimination decreases at higher values. In Models 2 and 4 an increase in education is negatively correlated with the use of violence, whilst an increase in wealth is positively correlated to the use of violence, with the effect of wealth increasing exponentially for each additional point increase on the IWI scale. All the models in Table 2 also show that women and older people are less likely support violence or use force, whilst urbanization has no significant relationship with either variable. We find no significant relationships between the group controls and either violence variable. Finally, the effect of the religious fractionalization index is not significant, suggesting that the presence of bridging ties do not appear to influence the individual's support for or use of violence.

\section{Discussion}

The aim of this study is to explore the relationship between social capital and violence by differentiating between the structural and cognitive components of social capital and empirically testing their association with political violence. This was achieved by examining associational membership and civic engagement as measures for structural social capital, and trust and national identity variables to gauge cognitive social capital. The expectation was that these different dimensions of social capital would have opposing associations to political violence. Prior research disaggregating social capital in this manner was limited to examining passive violence in single cases by measuring the respondents' exposure to violence (Dinesen et al. 2013; Hansen-Nord et al. 2014).Our research expands on prior findings by examining the relationship between different types of social capital and support for and use of political violence.

The findings were consistent for both forms of reported violence, although coefficients of social capital variables were more significant for the use of violence. Consistent with prior research (Dinesen et al. 2013; El Hajj et al. 2011; Hansen-Nord et al. 2014), the results lend strong support for the positive association between structural social capital and 
violence; higher levels of associational membership increase the risk of violence. Access to organized networks is theorized to provide individuals more opportunities to engage in collective action and any grievances incurred by the groups may be quickly diffused through the network. There is a risk that collective action may turn violent, especially when associations have a history of violence or leaders seeking to advance their own interests wield their influence within groups to mobilize their members towards collective action (Fearon and Laitin 2000). Violent behaviour appears to be more prevalent with community leaders than with religious leaders. De Figueiredo and Weingast's study (1999) provides a possible explanation. In their model of ethnic war, ethnic "entrepreneurs" might utilize violence to instill fear in other members of their ethnic group in order to manipulate and mobilize them into conflicts that benefit their own material interests and political aspirations.

Evidence supporting a negative association between cognitive social capital and violence is less strong, as we obtain contradicting results for the trust variables and insignificant effects in the multivariate models for national identity. The negative correlation between particularized trust and violence corresponds to the hypothesis on cognitive social capital, as well as prior research on trust on the neighbourhood level (Dinesen et al. 2013; Vial et al. 2010). In contrast to our expectations and other studies (Delhey and Newton 2005; Kasara 2017), we find a positive association between generalized trust and reported violence. However, this result is less consistent than that for the particularized trust variable, which was significant for both support for and the use of violence.

This inconsistency has been noted in other studies as well. Beugelsdijk (2006), for example, asserts that macro measures of trust are less fine-grained than micro measures, as they may be capturing an abstract confidence in society and its institutions rather than trust in people. Research comparing generalized and particularized trust finds that trust in neighbours is more strongly connected to community-based social capital than trust in 'others'. As Aghajanian (2016) points out, groups might trust their own members but not members of others outside of their immediate community, so measures of general trust may not be very robust indicators of social capital. Furthermore, by asking whether the respondent trusts 'most' people, the generalized trust question can be interpreted differently by each individual. This is known as the trust radius problem, and varies significantly across countries, making cross-country comparison difficult (Delhey, Newton and Welzel 2011). Nevertheless, the result for the generalized trust variable remains quite puzzling and deserves more attention in further research.

The other important finding in this study is that how closely one identifies with their identity is an important indicator of their support for and participation in violence. This finding is notable because any effect of norm adherence to a particular identity on social cohesion and potential violence is contingent on the sense of belonging to their identity (Wimberley 1989; Langer et al. 2017). The strength of attachment to one's identity may determine how intensely individuals perceive collective grievances, and therefore how easily they may be mobilized towards violent collective action. The effect of identity salience does not appear to be contingent on the individual's identity being tied to national identity, in contrast to previous findings (Sambanis and Shayo 2013; Charnysh et al. 2015).

One explanation for this could be found in the nature of the conflict itself. Identity conflicts are not always between competing identities on the ethnic level, but may also be a struggle between the ethnic and the national. For example, secessionist conflicts often occur between members of an ethnic group/region and the government. Supporters of the government involved in counter-protests or other forms of violence are likely to associate themselves with their national identity, in comparison with the rebellious ethnic group. In this case, the reason they participate in violence is because they are so strongly attached to 
their national identity. Another factor could be that when there is a dominant ethnic group in the country, the 'national' identity is appropriated by that group, such as the Tswana in Botswana or the Han in China. Members of these groups will perceive their ethnic identity to be synonymous with the national identity due to their monopoly on power and society in general (Staerklé et al. 2010). They view an attack against their ethnic group as an attack against the nation. This means that the variable comparing ethnic identity and national identity could actually be capturing the ethnic identity for both minority and majority groups in a country.

The story we draw from the control variables is that the types of individuals most prone to violent attitudes and behaviour are young, uneducated men. This is consistent with the findings of cross-national research on youth bulges and conflict (Urdal 2006). Group characteristics are found to be insignificantly related to reported violence, despite evidence for the Sub-Saharan African region suggesting socioeconomic and political factors are salient indicators of conflict (Alcorta et al. 2018). However, individual perception of collective grievances are found to be significantly and positively correlated to support for violence. Subjective perceptions of individuals and actual inequalities do not always match, but perceptions are what ultimately matter in the decision to engage in violence (Rustad 2016; Miodownik and Nir 2016).

Given that only cross-sectional data was available, our results cannot be interpreted in causal terms. The study's main aim is to determine the relationship between social capital and violence, however it frames the hypotheses in the direction of social capital influencing conflict. The logic behind this reasoning is that social capital can be viewed as the social relations through which mechanisms shape group dynamics and mobilize groups towards conflict (Schaub 2014). Nevertheless, the inability to make causal inferences means that the direction of this relationship should be considered. The literature on social capital suggests that the opposite relationship is also possible. For instance, some studies examining the effects of conflict purport that violence might foment discord and reduce trust between members within a community, subsequently reducing the level of cognitive social capital (De Luca and Verpoorten 2015; McIlwaine and Moser 2001). In contrast, other studies question whether conflict actually has an erosive effect on social capital (Cassar et al. 2013; Deng 2010; Goodhand et al. 2000). The causal relationship might run both ways in an endogenous relationship - high levels of structural social capital could raise the risk of violence breaking out, and high levels of violence over time might lead to the erosion or alteration of social capital (Ingelaere and Verpoorten 2016; Rohner et al. 2013; Schaub 2014). In the multivariate analysis, we control for this effect to some extent with the dummy on whether the group has been involved in conflict in the past. However, it is limited to the group level and does not capture individual violence or (inter)national conflict which may affect the respondent. Further research integrating conflict events data with the Afrobarometer surveys will be able to incorporate more robust controls for prior conflict.

\section{Conclusion}

In this study, we drew on 40,455 individual-level observations from 27 different countries from round five of the Afrobarometer surveys. We find a positive relationship between structural social capital and self-reported support for and use of political violence, whilst cognitive social capital and self-reported support for and use of political violence are negatively related. These findings highlight the importance of disaggregating social capital 
by its different dimensions, in order to better understand its relationship with violence. Additionally, we find that the salience of identity is a relevant factor in determining both receptivity to violence and violent behaviour. This finding suggests that a strong emotional attachment to a social identity, regardless of whether it is ethnic or national, is likely to stimulate individuals to take up arms for a political cause. The purpose of this research is not to discourage the accumulation of social capital, as its benefit to society is evident in the literature. However, policymakers looking to curtail violence within their communities should take note of the complex effects that strengthening civil society and social identities may have and consider a multifaceted approach when designing programs aimed at building social capital.

Open Access This article is licensed under a Creative Commons Attribution 4.0 International License, which permits use, sharing, adaptation, distribution and reproduction in any medium or format, as long as you give appropriate credit to the original author(s) and the source, provide a link to the Creative Commons licence, and indicate if changes were made. The images or other third party material in this article are included in the article's Creative Commons licence, unless indicated otherwise in a credit line to the material. If material is not included in the article's Creative Commons licence and your intended use is not permitted by statutory regulation or exceeds the permitted use, you will need to obtain permission directly from the copyright holder. To view a copy of this licence, visit http://creativecommons.org/licenses/by/4.0/.

\section{References}

Abbott, S., \& Freeth, D. (2008). Social capital and health: Starting to make sense of the role of generalized trust and reciprocity. Journal of Health Psychology, 13(7), 874-883.

Afrobarometer Data, Round 5. (2012). http://www.afrobarometer.org. Accessed 25 June 2018.

Aghajanian, A. J. (2016). Social capital and conflict: Impact and implications. Doctoral thesis (PhD), University of Sussex. https://EconPapers.repec.org/RePEc:sus:susphd:0116. Accessed 31 October 2018.

Alcorta, L., Smits, J., \& Swedlund, H. J. (2018). Inequality and ethnic conflict in Sub-Saharan Africa. Social Forces, 97(2), 769-792.

Allansson, M., Melander, E., \& Themnér, L. (2017). Organized violence 1989-2016. Journal of Peace Research, 54(4), 574-587.

Allison, P. D. (2001). Missing data. London: Sage Publications Ltd.

Avdeenko, A., \& Gilligan, M. J. (2015). international interventions to build social capital: Evidence from a field experiment in Sudan. American Political Science Review, 109(3), 427-449.

Beugelsdijk, S. (2006). A note on the theory and measurement of trust in explaining differences in economic growth. Cambridge Journal of Economics, 30(3), 371-387.

Bhavnani, R., \& Backer, D. (2007). Social capital and political violence in sub-Saharan Africa. Afrobarometer working paper no. 90.

Bisung, E., Elliott, S. J., Schuster-Wallace, C. J., Karanja, D. M., \& Bernard, A. (2014). Social capital, collective action and access to water in rural Kenya. Social Science and Medicine, 119, 147-154.

Blattman, C., \& Miguel, E. (2010). Civil war. Journal of Economic Literature, 48(1), 3-57.

Brehm, J., \& Rahn, W. (1997). Individual-level evidence for the causes and consequences of social capital. American Journal of Political Science, 41(3), 999-1023.

Brune, N., \& Bossert, T. (2009). Building social capital in post-conflict communities: Evidence from Nicaragua. Social Science and Medicine, 68(5), 885-893.

Carpiano, R. M., \& Fitterer, L. M. (2014). Questions of trust in health research on social capital: What aspects of personal network social capital do they measure? Social Science and Medicine, 116, $225-234$.

Cassar, A., Grosjean, P., \& Whitt, S. (2013). Legacies of violence: Trust and market development. Journal of Economic Growth, 18(3), 285-318.

Charnysh, V., Lucas, C., \& Singh, P. (2015). The ties that bind: National identity salience and pro-social behavior. Comparative Political Studies, 48(3), 267-300.

Coleman, J. S. (1990). Foundations of social theory. Cambridge: Harvard University Press.

Colletta, N. J., \& Cullen, M. L. (2000). Violent conflict and the transformation of social capital: Lessons from Cambodia, Rwanda, Guatemala, and Somalia. Washington, D.C.: The World Bank. http://docum 
ents.worldbank.org/curated/en/799651468760532921/Violent-conflict-and-the-transformation-of-socia 1-capital-lessons-from-Cambodia-Rwanda-Guatemala-and-Somalia.

Cuesta, J., \& Alda, E. (2012). The effects of trust on victimization in Colombia. Journal of Peace Research, 49(6), 833-846.

Dasgupta, P., \& Serageldin, I. (Eds.). (2000). Social capital: A multifaceted perspective., Sociological perspectives on development series Washington, D.C.: The World Bank.

de Figueiredo, R., \& Weingast, B. (1999). Rationality of fear: Political opportunism and ethnic conflict. In B. Walter \& J. Snyder (Eds.), Military intervention in civil wars (pp. 261-302). New York: Columbia University Press.

de Luca, G., \& Verpoorten, M. (2015). Civil war and political participation: Evidence from Uganda. Economic Development and Cultural Change, 64(1), 113-141.

de Silva, M. J., Harpham, T., Tuan, T., Bartolini, R., Penny, M. E., \& Huttly, S. R. (2006). Psychometric and cognitive validation of a social capital measurement tool in Peru and Vietnam. Social Science and Medicine, 62(4), 941-953.

Delhey, J., \& Newton, K. (2005). Predicting cross-national levels of social trust: Global pattern or nordic exceptionalism? European Sociological Review, 21(4), 311-327.

Delhey, J., Newton, K., \& Welzel, C. (2011). How general is trust in "most people"? Solving the radius of trust problem. American Sociological Review, 76(5), 786-807.

Deng, L. B. (2010). Social capital and civil war: The Dinka communities in Sudan's civil war. African Affairs, 109(435), 231-250.

Dinesen, C., Ronsbo, H., Juárez, C., González, M., Estrada Méndez, M. A., \& Modvig, J. (2013). Violence and social capital in post-conflict Guatemala. Pan American Journal of Public Health, 34, $162-168$.

Dowla, A. (2006). In credit we trust: Building social capital by Grameen Bank in Bangladesh. The Journal of Socio-Economics, 35(1), 102-122.

Eck, K., \& Hultman, L. (2007). Violence against civilians in war. Journal of Peace Research, 44(2), 233-246.

El Hajj, T., Afifi, R. F., Khawaja, M., \& Harpham, T. (2011). Violence and social capital among young men in Beirut. Injury Prevention, 17(6), 401-406.

Fearon, J. D., \& Laitin, D. D. (2000). Violence and the social construction of ethnic identity. International Organization, 54(4), 845-877.

Fukuyama, F. (2000). Social capital and civil society. IMF working paper No. 00/74. Washington, DC.

Glanville, J. L., \& Paxton, P. (2007). How do we learn to trust? A confirmatory tetrad analysis of the sources of generalized trust. Social Psychology Quarterly, 70, 230-242.

Goodhand, J., Hulme, D., \& Lewer, N. (2000). Social capital and the political economy of violence: A case study of Sri Lanka. Disasters, 24(4), 390-406.

Grosjean, P. (2014). Conflict and social and political preferences: Evidence from world war II and civil conflict in 35 European countries. Comparative Economic Studies, 56(3), 424-451.

Hansen-Nord, N. S., Kjaerulf, F., Almendarez, J., Morales Rodas, V., \& Castro, J. (2016). Reducing violence in poor urban areas of Honduras by building community resilience through community-based interventions. International Journal of Public Health, 61(8), 935-943.

Hansen-Nord, N. S., Skar, M., Kjaerulf, F., Almendarez, J., Bähr, S., Sosa, O., et al. (2014). Social capital and violence in poor urban areas of Honduras. Aggression and Violent Behavior, 19(6), 643-648.

Hardin, R. (2002). Trust and trust worthiness. New York: Russell Sage Foundation.

Holtug, N. (2017). Identity, causality and social cohesion. Journal of Ethnic and Migration Studies, 43(7), 1084-1100.

Ingelaere, B., \& Verpoorten, M. (2016). Inter-ethnic trust in the aftermath of mass violence: Insights from large-N life histories. IOB working papers 2016.03. Universiteit Antwerpen, Institute of Development Policy (IOB).

Kasara, K. (2017). Does local ethnic segregation lead to violence?: Evidence from Kenya. Quarterly Journal of Political Science, 11(4), 441-470.

Krishna, A., \& Shrader, E. (2000). Cross-sectoral measures of social capital: A tool and results from India and Panama. Social capital initiative working paper no. 21. Social Development Department, World Bank, Washington, DC.

Langer, A., Stewart, F., Smedts, K., \& Demarest, L. (2017). Conceptualising and measuring social cohesion in Africa: Towards a perceptions-based index. Social Indicators Research, 131(1), 321-343.

Lederman, D., Loayza, N., \& Menéndez, A. (2002). Violent crime: Does social capital matter? Economic Development and Cultural Change, 50(3), 509-539.

Lemarchand, R. (1996). Burundi: Ethnic conflict and genocide. Cambridge: Cambridge University Press. 
Levi, M. (1998). A state of trust. In V. Braithwaite \& M. Levi (Eds.), Trust and governance (pp. 77-101). New York: Russell Sage Foundation.

Linke, A. M., Schutte, S., \& Buhaug, H. (2015). Population attitudes and the spread of political violence in sub-saharan Africa. International Studies Review, 17(1), 26-45.

McDougall, C., \& Banjade, M. R. (2015). Social capital, conflict, and adaptive collaborative governance: Exploring the dialectic. Ecology and Society, $20(1), 44$.

McIlwaine, C., \& Moser, C. O. M. (2001). Violence and social capital in urban poor communities: Perspectives from Colombia and Guatemala. Journal of International Development, 13(7), 965-984.

Miodownik, D., \& Nir, L. (2016). Receptivity to violence in ethnically divided societies: A micro-level mechanism of perceived horizontal inequalities. Studies in Conflict \& Terrorism, 39(1), $22-45$.

Mitchell, A. D., \& Bossert, T. J. (2007). Measuring dimensions of social capital: Evidence from surveys in poor communities in Nicaragua. Social Science and Medicine, 64(1), 50-63.

Ostrom, E., \& Ahn, T. K. (2009). The meaning of social capital and its link to collective action. In G. T. Svendsen \& G. L. H. Svendsen (Eds.), Handbook of social capital: The Troika of sociology, political science and economics (pp. 17-35). Northampton, MA: Edward Elgar Publishing.

Piquet Carneiro, L. (2000). Violent crime in Latin American cities: Rio de Janeiro and São Paulo. Washington: World Bank.

Portes, A. (1998). Social capital: Its origins and applications in modern sociology. Annual Review of Sociology, 24(1), 1-24.

Purdeková, A. (2008). Building a nation in Rwanda? De-ethnicisation and its discontents. Studies in Ethnicity and Nationalism, 8(3), 502-523.

Putnam, R. D. (1993). Making democracy work: Civic transitions in modern Italy. Princeton, NJ: Princeton University Press.

Putnam, R. D. (2000). Bowling alone: The collapse and revival of American community. New York: Simon and Schuster.

Reynal-Querol, M. (2002). Ethnicity, political systems, and civil wars. Journal of Conflict Resolution, $46(1), 29-54$.

Robinson, A. L. (2016). Nationalism and ethnic-based trust: Evidence from an African border region. Comparative Political Studies, 49(14), 1819-1854.

Rohner, D., Thoenig, M., \& Zilibotti, F. (2013). War signals: A theory of trade, trust, and conflict. The Review of Economic Studies, 80(3), 1114-1147.

Rosenfeld, R., Baumer, E. P., \& Messner, S. F. (2001). Social capital and homicide. Social Forces, 80(1), 283-310.

Rubio, M. (1997). Perverse social capital: Some evidence from Colombia. Journal of Economic Issues, 31(3), 805-816.

Rudolph, T. J., \& Popp, E. (2010). Race, environment, and interracial trust. The Journal of Politics, 72(1), 74-89.

Rustad, S. (2016). Socioeconomic inequalities and attitudes toward violence: A test with new survey data in the Niger Delta. International Interactions, 42(1), 106-139.

Sambanis, N., \& Shayo, M. (2013). Social identification and ethnic conflict. American Political Science Review, 107(2), 294-325.

Sampson, R. J., \& Raudenbush, S. W. (1999). Systematic social observation of public spaces: A new look at disorder in urban neighborhoods. American Journal of Sociology, 105(3), 603-651.

Schaub, M. (2014). Solidarity with a sharp edge: Communal conflict and local collective action in rural Nigeria. HiCN working papers 183, Households in Conflict Network.

Shahabuddin McDoom, O. (2014). Antisocial capital: A profile of Rwandan genocide perpetrators' social networks. Journal of Conflict Resolution, 58(5), 865-893.

Smith, S. S. (2010). Race and trust. Annual Review of Sociology, 36(1), 453-475.

Smits, J., \& Steendijk, R. (2015). The international wealth index (IWI). Social Indicators Research, 122(1), 65-85.

Staerklé, C., Sidanius, J., Green, E. G., \& Molina, L. E. (2010). Ethnic minority-majority asymmetry in national attitudes around the world: A multilevel analysis. Political Psychology, 31(4), 491-519.

Stewart, F. (Ed.). (2008). Horizontal inequalities and conflict: Understanding group violence in multiethnic societies. London: Palgrave MacMillan.

Sundberg, R., Eck, K., \& Kreutz, J. (2012). Introducing the UCDP non-state conflict dataset. Journal of Peace Research, 49(2), 351-362.

Sztompka, P. (1999). Trust: A sociological theory. Cambridge: Cambridge University Press.

Uphoff, N. (2000). Understanding social capital: Learning from the analysis and experience of participation. In P. Dasgupta \& I. Serageldin (Eds.), Social capital: A multifaceted perspective (pp. 215252)., Sociological perspectives on development series Washington, D.C: The World Bank. 
Uphoff, N., \& Wijayaratna, C. M. (2000). Demonstrated benefits from social capital: The productivity of farmer organizations in Gal Oya, Sri Lanka. World Development, 28(11), 1875-1890.

Urdal, H. (2006). A clash of generations? Youth bulges and political violence. International Studies Quarterly, 50(3), 607-630.

Uslaner, E. M. (2002). The moral foundations of trust. Cambridge: Cambridge University Press.

Varshney, A. (2001). Ethnic conflict and civil society: India and beyond. World Politics, 53(3), 362-398.

Vazquez-Rodriguez, A., \& Lombe, M. (2017). Assessing social engagement in unstable environments: An examination of collective action in Mexico. Global Social Welfare, 4(4), 233-246.

Vial, E. A., Junges, J. R., Olinto, M. T. A., Machado, P. S., \& Pattussi, M. P. (2010). Violência urbana e capital social em uma cidade no Sul do Brasil: um estudo quantitative e qualitativo. Revista Panamericana de Salud Pública, 28(4), 289-297.

Villalonga-Olives, E., \& Kawachi, I. (2017). The dark side of social capital: A systematic review of the negative health effects of social capital. Social Science and Medicine, 194, 105-127.

Vogt, M., Nils-Christian, B., Seraina, R., Lars-Erik, C., Philipp, H., \& Luc Girardin. (2015). Integrating data on ethnicity, geography, and conflict: the ethnic power relations dataset family. Journal of Conflict Resolution, 59(7), 1327-1342.

Wimberley, D. (1989). Religion and role-identity: A structural symbolic interactionist conceptualization of religiosity. The Sociological Quarterly, 30(1), 125-142.

World Bank. (2011). World development report 2011: Conflict, security, and development. World Bank.

Wright, D. R., \& Fitzpatrick, K. M. (2006). Violence and minority youth: The effects of risk and asset factors on fighting among African American children and adolescents. Adolescence, 41(162), 251-262.

Publisher's Note Springer Nature remains neutral with regard to jurisdictional claims in published maps and institutional affiliations. 